\title{
Assessment of major reproductive disorders of dairy cattle in urban and per urban area of Hosanna, Southern Ethiopia
}

\author{
Adane Haile ${ }^{1}$, Yisehak Tsegaye ${ }^{2}$, Niguse Tesfaye ${ }^{2}$ \\ ${ }^{1}$ Department of Animal Science, Faculty of Agricultural Sciences, Wachemo University, P.O.Box: 667, SNNP, Ethiopia \\ ${ }^{2}$ College of Veterinary Medicine, Mekelle University, Tigray, Ethiopia
}

\section{Email address:}

adanehaile37@gmail.com (A. Haile),niguseyel73@gmail.com (N. Tesfaye), nahomlove1@yahoo.com (Y. Tsegaye)

\section{To cite this article:}

Adane Haile, Yisehak Tsegaye, Niguse Tesfaye. Assessment of Major Reproductive Disorders of Dairy Cattle in Urban and Per Urban Area of Hosanna, Southern Ethiopia. Animal and Veterinary Sciences. Vol. 2, No. 5, 2014, pp. 135-141.

doi: $10.11648 /$ j.avs. 20140205.11

\begin{abstract}
The study which employed both questionnaire and observational survey was conducted in urban and per urban area of Hossana with the objectives of determining the prevalence of major reproductive health problems of dairy cattle and the possible risk factors in the selected dairy farms from November 2013 to April 2014. A total of 390 dairy cattle (349 cross and 41 local breed) which were kept under different management system (256 intensively, 60 semi intensively and 74 were extensive) were included, out of which $43.07 \%(n=168)$ were found to be affected either with one or more of reproductive problems. Repeat breeder, anoestrus, Retained Fetal membrane (RFM), and dystocia were found to be the major reproductive health problems containing $13.08 \%, 12.06 \%, 7.18 \%$ and $5.9 \%$ prevalence rate respectively and other reproductive health problems observed with lower prevalence include vaginal prolapsed, abortion, mixed and uterine prolapsed having $3.44 \%, 2.56 \%, 1.03 \%$, and $0.76 \%$ respectively in the study farms of the area. The overall prevalence of reproductive problems showed significant difference $(\mathrm{p}<0.05)$ with respect to body condition and parity of dairy cattle where major reproductive health problems were observed more frequently in poor body conditioned and pluriparus cows. Whereas breed and management system were not found to have a significant influence $(p>0.05)$ on the occurrence of reproductive problems in the area. Therefore, it is recommended that awareness creation to farm owners, attendants and improved management such as, proper feeding, accurate heat detection, considering the size of sire and dam while using AI, and health management should be improved to minimize the occurrence of these problems and associated economic losses in the dairy farms of the area.
\end{abstract}

Keywords: Cattle, Ethiopia, Hosanna, Reproductive Health, Risk Factors

\section{Introduction}

Ethiopia has the largest livestock population being the first in Africa countries and the 10th in the world. However, dairy industry is not developed as that of other east African countries such as Kenya, Uganda and Tanzania [35].

Despite the huge number of cattle and their economic importance, the productivity is low due to the constraints of disease, nutrition, poor management, lack of marketing facilities and opportunity, inadequate animal health services, uncoordinated development programs between various levels of government institutions and /or non-government organizations and poor performance of indigenous breeds.
These constraints result in poor reproductive performance of dairy cattle [6].

In the last few decades, as the major epidemic disease, were brought under control, emphasis have increasingly shifted to economically important diseases to the dairy producers and reproductive health problem stands out as the most prominent [26]. Regular breeding depends upon the normal function of the reproductive system. In order to breed regularly, the cow has to have functional ovaries, display estrous behavior, mate, conceive, sustain the embryo through gestation, calve, and resume estrous cyclicity and restore uterine function after calving. Each of these aspects of reproductive function can be affected by management, disease and the genetic make-up of the 
animal. When the function of the reproductive system is impaired, cows fail to produce a calf regularly. Among the major reproductive problems that have direct impact on reproductive performance of dairy cows are abortion, dystocia, Retained Fetal Membrane (RFM), pyometra, metritis, prolapse (uterine and vaginal), anoestrus and repeat breeder. They are classified as before gestation (anoestrous and repeat breeding), during gestation (abortion, vagina prolapsed and dystocia) and after gestation (retained fetal membrane and uterine prolapsed) [2, 13, 29, 18].

Upon closer examination of reproductive processes in the dairy cattle, the post-partum period is the most varied and vulnerable to problems and that incidentally coincides with the peak of milk production, uterine involution, and resumption of ovarian activity, conception and greater risk to infection [25]. These result in considerable economic loss to the dairy industry due to slower uterine involution, reduced reproductive rate, prolonged inter-conception and calving interval, negative effect on fertility, increased cost of medication, drop in milk production, reduced calf crop and early depreciation of potentially useful cows [10, 18]. But in dairy industry the reproductive goals that we need to follow are 12 months of calving interval, 85 days open, 1.6 services per conception rate and $85 \%$ of cows observed in estrus and recorded by 60 days fresh [22]. It is very difficult to diagnose those problems by one particular disorder or symptom because there is interrelation between predisposing factors such as management at calving, hygiene and parity, stage of gestation, nutrition and environment $[8,22]$.

Reproductive disorder of dairy animals was broadly studied throughout the world, but studies in Ethiopia are limited and mainly located in central high lands and in some parts of Eastern and Northern parts of the country. Although, major reproductive disorders greatly responsible for high economic loss in dairy cows, there is paucity of research done on the prevalence, etiology and relative importance of these problems in Hosanna. Therefore, the present investigation had been planned to study: the prevalence of major reproductive health problems of dairy cattle in Hosanna and possible risk factors that play a role in precipitating such problems in dairy farms of the area.

\section{Materials ad Methods}

\subsection{Study Area}

The study was conducted in southern Ethiopia, Hadiya zone, Hosanna town. Topographically the zone lies within an elevation range of 1500 to3000 meters above sea level. The zone has three agro- ecological / zones. Dega (23.7\%), Weyna dega (64.7) and Kolla (11.6\%). The annual average temperature of the zone is $22.02^{\circ} \mathrm{C}$ and the mean annual rainfall is $1260 \mathrm{~mm}$. Hosanna town is the administrative and trading center of the zone. The town is located at a distance of $231 \mathrm{~km}$ south of Addis Ababa and $160 \mathrm{~km}$ west of Hawassa town. Hosanna has a latitude and longitude of $7^{\circ} 33^{\prime} \mathrm{N} 37^{\circ} 51^{\prime} \mathrm{E}$, with an elevation of $1500-2177$ meters above sea level. The annual average temperature of the town is $14.4^{\circ} \mathrm{C}$ and the average annual rainfall is 1331.6 mm (SNNBPOA, 1997).

\subsection{Sample Size and Study Animals}

A total of 390 dairy cattle with different parity, management and body conditions were included in this study. Both non descriptive indigenous $(n=41)$ and cross $(n=349)$ breeds dairy cattle which were kept under different management systems was also investigated. Classification of management systems was done based on the criteria adopted by Richard [27].

\subsection{Study Design}

The cross-sectional type of study was under taken from November 2013 to April 2014 in purposively selected dairy farms in and around Hosanna, to determine the major reproductive problems of dairy cattle and the study employed questionnaire and regular follow up.

\subsection{Data Collection}

\subsubsection{Questionnaires Survey Method}

Structured questionnaire was prepared and used to collect information from 45 dairy farm owners in one visit interview and reproductive problems of their dairy cattle on individual level were studied. The questionnaires were checked for clarity of the questions prior the interview. Prior the interview, respondents were briefed to the objective of the study by using local language. Following that, the actual questions and questionnaires were presented. Accordingly, information about the parity, breed, feeding system, production system, and type of feed, health care and major reproductive problems such as abortion, anoestrus and repeat breeder were collected on individual cattle level.

\subsubsection{Observational Study (Longitudinal)}

\subsubsection{Questionnaires Survey Method}

Structured questionnaire was prepared and used to collect information from 45 dairy farm owners in one visit interview and reproductive problems of their dairy cattle on individual level were studied. The questionnaires were checked for clarity of the questions prior the interview. Prior the interview, respondents were briefed to the objective of the study by using local language. Following that, the actual questions and questionnaires were presented. Accordingly, information about the parity, breed, feeding system, production system, and type of feed, health care and major reproductive problems such as abortion, anoestrus and repeat breeder were collected on individual cattle level.

A regular visit was carried out once per weeks on 6 dairy farms which was purposively selected on the basis of animal size, facility availability, ease of access, production system, breed, and on systematic randomly selected 58 
dairy cattle from 116 out of 390 to collect data on the major reproductive problems. The study animals were identified by their tag number/ID, parity and pregnant animals that were suspected to give birth within the study period and heifer that has age of 2 year and above were included and followed up from the start to the end of study period. To do this observational format was prepared and filled so as to increase the reliability of information collected in questionnaire. Cows that delivered were observed for the presence of retained fetal membrane left hanging in the vulva in the first $24 \mathrm{~h}$ and if any abnormal vaginal discharge occurred without regular frequency of visit.

\subsubsection{Body condition Scoring}

For all of the animals under study, body condition was scored in order to assess the nutritional status of the animal and the prevalence of reproductive problems. Therefore, animals were grouped in to $0,1,2,3,4$ and 5 body condition scores according to Richard [27]. The measurement was done through palpation and visualization of the transverse and spines processes for the lumbar vertebrae (loin) and tail head respectively.

\subsection{Data Management and Analysis}

The data obtained from questionnaire and regular follow up were entered on a Microsoft Excel spreadsheet and analyzed using Statistical Package for Social Sciences version16 [31]. The prevalence of reproductive problems was determined as a proportion of affected animals out of the total animal examined. The differences or association between in different risk factors such as breed, parity, production system and body condition with over all prevalence of reproductive problems was analyzed by using $\chi^{2}$ (Chi-square) technique and value of $\mathrm{p}<0.05$ considered as significant.

\section{Results}

\subsection{Questionnaire Study}

Based on the questionnaire study out of 45 respondents $41(91.1 \%)$ were males and $4(8.9 \%)$ were females, and as observed from the educational level of farm owners or attendants, $18(40 \%)$ were illiterate, and the rest $27(60 \%)$ were literate. With regard to the location of the farms, 28 $(62.22 \%)$ were found in the urban location and $17(37.78 \%)$ were in peri- urban area.

\subsubsection{Animals' Management}

From the total of 390 dairy cattle, $256(65.64 \%)$ were managed intensively, 60 (15.4\%) were semi intensive and 74 (19\%) were extensively and of which 349 (89.4\%) were cross breed and the rest $41(10.6 \%)$ were local breed. Almost the entire respondent agreed that feeding practice depends on the availability of feed because land space and water that is important factors for cultivation of animal feed is limited in the farm area. The feed on which the animals are fed include natural pasture (cut-and-carry), grass hay, straw, milling by- products(frushka), dairy concentrate mix, crop residues, some green grasses like alfa alfa, elephant grass and nonconventional feeds such as" inset" and "atela" were among the commonest and mainly available feed types.

Most of the respondents $(66.7 \%)$ breed their animals using AI. (20\%) $(n=9)$ of the farms practiced both AI and natural service. $13.3 \%(\mathrm{n}=6)$ use only natural method. $88 \%$ $(n=40)$ respondent said that estrus detection were observed by herd watch men and $11.9 \%(n=5)$ of respondent said it was detected by farm owner and animal health technicians and veterinarians from surrounding clinics. As replied by the respondent, there was no regular vaccination and deworming practices but they took their animals for treatment whenever diseases occurred.

\subsubsection{Major Reproductive Disease Identified}

Table 1. Summary of prevalence rate of major reproductive problems of dairy Cattle in Hosanna encounterd by questionairy study.

\begin{tabular}{lcc}
\hline $\begin{array}{l}\text { Major reproductive problems } \\
\text { encountered }\end{array}$ & Total & Prevalence (\%) \\
\hline Abortion & 10 & 2.56 \\
Anoestrus & 40 & 10.26 \\
Dystocia & 24 & 5.9 \\
Repeat breeding & 51 & 13.08 \\
Retained placenta & 28 & 7.18 \\
Uterine prolapse & 3 & 0.76 \\
Vaginal prolapse & 8 & 2.05 \\
Mixed* & 4 & 1.03 \\
Total & 168 & 43.07 \\
\hline
\end{tabular}

*Mixed problems include abortion and retained placenta, anestrus and repeat breeding, and dystocia and retained placenta ( 2 cases).

The major reproductive problems identified were anestrous (10.26\%) and repeat breeding (13.08\%), as summarized on table1. In this study $43.07 \%(n=168)$ cattle were found affected by either one or more of reproductive problems.

\subsubsection{Association of Risk Factors with Reproductive Health Problems of Dairy Cattle}

In this study among risk factors production system, breed, parity and body condition score were considered to assess its association with the occurrence of the reproductive problems as shown on the tables below.

Table 2. Prevalence and association of reproductive problems with breed and production systems.

\begin{tabular}{lccccc}
\hline $\begin{array}{l}\text { Breeds of } \\
\text { cows }\end{array}$ & $\begin{array}{c}\text { No. animals } \\
\text { examined }\end{array}$ & $\begin{array}{c}\text { No. of } \\
\text { affected } \\
\text { Animals }\end{array}$ & $\begin{array}{c}\text { Percenta } \\
\text { ge(\%) }\end{array}$ & $\mathbf{X}^{\mathbf{2}}$ & $\begin{array}{c}\text { p- } \\
\text { value }\end{array}$ \\
\hline Local & 41 & 17 & 41.46 & & \\
Cross & 349 & 151 & 43.26 & 9.80 & 0.633 \\
Total & 390 & 168 & 43.07 & & \\
Production & & 106 & 41.40 & & \\
system & 256 & 28 & 46.7 & & \\
Intensive & 60 & 34 & 45.9 & & \\
Semintensive & 74 & 168 & 43.07 & & \\
Extensive & 390 & & & & \\
Total & & & & & \\
\hline
\end{tabular}


As shown on the table 2 above, statistically no significant difference $(\mathrm{P}>0.05)$ was found in the prevalence of reproductive health problems with respect to breed and management system.

The influence of body condition score on the occurrence of the major reproductive problems was also assessed (Table 3) and the result showed that there is statistically significant $(p<0.05)$ variation with regard to body condition scores that ranged from 0 to 5 . Highest prevalence was found in cattle with body condition score 1 followed by body condition score 2 while the least in cows with body condition score 3 .

Table 3. Prevalence and association of major reproductive problems with body condition.

\begin{tabular}{llllll}
\hline BCS & $\begin{array}{r}\text { No. cattle } \\
\text { examined }\end{array}$ & $\begin{array}{c}\text { No. of } \\
\text { affected }\end{array}$ & $\begin{array}{c}\text { Prevalence } \\
(\%)\end{array}$ & $\mathbf{X}^{2}$ & $\begin{array}{c}\text { P- } \\
\text { value }\end{array}$ \\
\hline 0 & 5 & 2 & 40 & & \\
1 & 12 & 11 & 91.67 & & \\
2 & 118 & 67 & 56.7 & & \\
3 & 242 & 83 & 34.3 & 73.94 & 0.000 \\
4 & 13 & 5 & 38.46 & & \\
5 & 0 & 0 & 0 & & \\
Total & 390 & 168 & 43.07 & & \\
\hline
\end{tabular}

Table 4. Prevalence and association of major reproductive problems with parity.

\begin{tabular}{llllll}
\hline Parity & $\begin{array}{l}\text { Total } \\
\text { examined }\end{array}$ & $\begin{array}{l}\text { Total } \\
\text { affected }\end{array}$ & $\begin{array}{l}\text { Percentage } \\
(\%)\end{array}$ & $\boldsymbol{X}^{\mathbf{2}}$ & $\boldsymbol{p}$.value \\
\hline Heifer & 97 & 33 & 34.02 & & 0.000 \\
$1-3$ & 261 & 113 & 43.29 & 52.15 & \\
$>3$ & 32 & 22 & 70.97 & & \\
Total & 390 & 168 & 43.07 & & \\
\hline
\end{tabular}

Parity had statistically significant effect $\left(\boldsymbol{X}^{2}=\mathbf{5 2} ; \mathrm{P}=0.000\right)$ on the prevalence of reproductive health problems with parity of more than three times being more susceptible to reproductive problems than heifer and parity of one to three times as shown below on table 4 .

As shown on the fig. 1 below; the high score of anoestrus and repeated breeder having $48.48 \%$ and $42.2 \%$ was in heifers; and the rest problems were high in pluriparus cows.

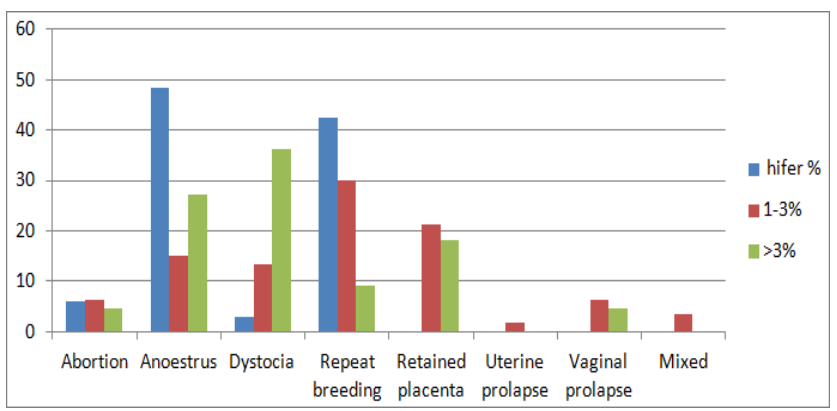

Fig. 1. Percentages of each of reproductive problems with respect to parity.

\subsection{Observational Study}

In this longitudinal study $\mathrm{n}=21(36.20 \%)$ animals were found to be affected either with one or more of reproductive problems. Anoestrus $(12.06 \%)$ was found to be the leading reproductive problem followed by repeat breeding $(8.62 \%)$, retained placenta $(6.89 \%)$, vagina prolapsed (prepartum) $(3.44 \%)$, dystocia $(1.72 \%)$, and abortion $(1.72 \%)$.

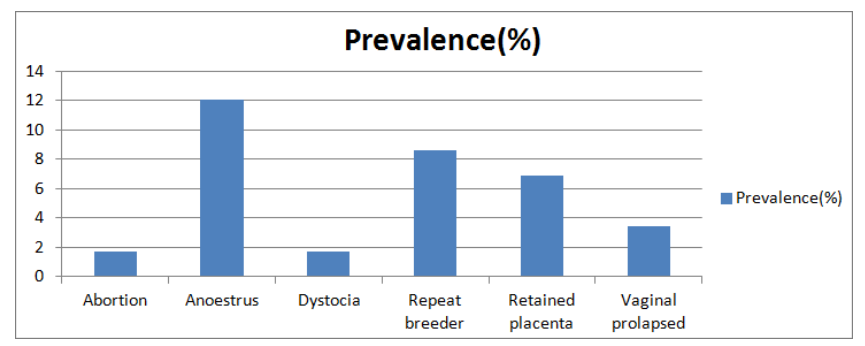

Fig. 2. Summary of reproductive problems encountered by observational survey.

Table 5. Percentage and association of major reproductive problems with parity and body condition score encountered by observational study.

\begin{tabular}{llllll}
\hline Parity & $\begin{array}{l}\text { Total } \\
\text { examined }\end{array}$ & $\begin{array}{l}\text { Total } \\
\text { affected }\end{array}$ & $\begin{array}{l}\text { Percentage } \\
(\%)\end{array}$ & $\mathbf{X}^{\mathbf{2}}$ & p-value \\
\hline Heifer & 15 & 3 & 20.00 & 10.15 & 0.017 \\
$1-3$ & 35 & 14 & 40.00 & & \\
$>3$ & 8 & 4 & 50.00 & & \\
Total & 58 & 21 & 36.20 & & \\
BCS & & & & & \\
0 & 0 & 0 & 0.00 & 50.83 & 0.001 \\
1 & 10 & 7 & 70.00 & & \\
2 & 17 & 6 & 35.59 & & \\
3 & 28 & 8 & 28.58 & & \\
4 & 3 & 0 & 0.00 & & \\
5 & 0 & 0 & 0.00 & & \\
Total & 58 & 21 & 36.20 & & \\
\hline
\end{tabular}

The present study revealed that there is statistically significant association $\left(X^{2}=50.83 ; \mathrm{P}=0.001\right)$ of reproductive health problems with BCS and parity (table 5); highest prevalence of reproductive health problems was found in cattle with body condition score 1 followed by body condition score 2, while the least in cows with body condition score 4, and the highest prevalence of reproductive health problems in pluriparus cows than heifer, and pluriparus cows being more susceptible to reproductive problems

\section{Discussion}

This study revealed, that male entrepreneurs (92\%) and educated one $(60 \%)$ cover majority of the dairy farm operations, showing that majority of dairying in Hosanna is mainly male domain and the majorities were educated and the majority of the farms $(62.22 \%)$ were located in urban area.

In the present study $43.3 \%(n=168)$ of dairy cattle in the study areas were affected by either one or more reproductive disorders based on questionnaires to the owners. This is in close agreement with the report by 
Hadush et al. [11] in central Ethiopia and Dawite and Ahmed [7] in Northeast Ethiopia who reported 44.3\% and $40.3 \%$ respectively, but higher than $18.5 \%$ which was reported by Hunduma [14] in Assela town and 26.5\% by Molalegne and Shiv [21] in Bedelle. This difference might be due to sample size, production system, study methodology and breed of animals as well as environmental factors.

In this study (including questionnaire and regular follow up) repeat breeder, anestrus, RFM, and dystocia were found to be the major reproductive health problems containing $13.08 \%, 12.06 \%, 7.18 \%$ and $5.9 \%$, respectively. Other reproductive health problems observed with lower prevalence include vaginal prolapsed, abortion, mixed and uterine prolapsed accounting 3.44\%, 2.56\%, 1.03\%, and $0.76 \%$ respectively.

The higher prevalence of repeated breeding (13.08\%) found in the present study is in close agreement with $13 \%$ reported by Micheal [20] in and around Hawassa, but higher than $11.42 \%$ prevalence rate reported by Hadush et al.[11] from central Ethiopia. Repeated breeding can be caused by a number of factors, including sub-fertile bulls, endocrine imbalance, malnutrition, reproductive tract infections and poor management practices such as wrong time of insemination or faulty heat detection, inappropriate semen handling and insemination techniques [2]. In addition to these, communal use of bull for natural services also considered as contributing factor. Hence the difference between the findings of the current study and previous reports may be attributed to the above-mentioned factors.

The prevalence of anestrous observed in this study $(12.26 \%)$ is in line with the results of Hadush et al. [11], who reported $12.9 \%$ in dairy cattle in Debre Zeit and lower than Befekadu [4] who reported $24 \%$ in cross breed dairy cows in central high lands of Ethiopia. This prevalence rate is also higher than the prevalence indicated by Amene [1] who reported a prevalence of $10.2 \%$ in Holstein Frisian cows at Alage dairy farm. This variation might be due to the age, faulty heat detection, breed and management system differences.

The prevalence rate of RFM (7.18\%) in recent study is similar with the $8.6 \%$ reported by Molalegn and Shiv [21], and but lower than (14.28\%) reported by Mamo, [19] and $19.2 \%$ by Gashaw et al., [9]. The variation in the incidence of RFM may be attributed to variations in predisposing factors to which the animals are subjected to; among which include nutritional status and management such as lack of exercise. The prevalence rate of RFM in the current study could also be due to dystocia that accounted $5.9 \%$ of the problems, which is an important predisposing factor for occurrence of RFM and higher report by Gashaw et al. [9] might be due to high report of (5.6\%) mixed problems than current (1.03\%), but Mamo, [19] calculated prevalence rate from positive animals not from total as current study.

Previous report on the prevalence of dystocia by Mamo [19] $(5.79 \%)$ in small holder dairy cows in and around DebreZeiet fairly agrees to the prevalence of $5.9 \%$ obtained in this study. However, the current finding is lower than the prevalence of $7.75 \%$ reported by Dawit and Ahmed [7], and higher than those of Gashaw et al. [9] (3.8\%) and Hadush et al. [11] (2.9\%). This variation in the occurrence of dystocia may be due to the fact that it is influenced by the factors such as, age and parity of the dam as well as breed of the sire. Inseminating cows with semen collected from large sized bulls without taking into account the size and age of cows is an important factor in precipitating dystocia [24].

The prevalence rate of abortion (2.56\%) recorded in this study is similar to the $2.23 \%$ reported by Bekana et al.,[5] in Nazret, but is lower than the $9.05 \%, 13.9 \%$ and $14.6 \%$ reported by Dawite and Ahmed[7], Molalegn and Shiv [21] and Hunduma, [14] respectively. The lower prevalence rate of abortion may be attributed to the increasing practice of AI in the study area $(66.7 \%)$ where the semen is collected from bulls free from brucellosis, in addition breed, management system specially feeding and sanitation, study methodology and geographical location differences are all sources of differences in prevalence of abortion[9].

The prevalence rate of vaginal prolapsed (3.44\%) recorded in this study is similar to the $5.2 \%$ reported by Kidusan [17] but is higher than the $1.24 \%$, and $1.95 \%$ reported by, Dawite and Ahmed [7], and Hadush et al. [11] respectively. This variation might be due to management system (feeding), sample size and breed of animals. The prevalence rate of mixed problems $(1.03 \%)$ recorded in this study is similar to the $1.05 \%$ reported by Simiret [30] in Mekelle, but lower than 5.6\% indicated by Gashaw et al. [9]. This variation could be due to inter relationship between of reproductive problems as predisposing factors for each other. Uterine prolapsed $(0.76 \%)$ is consistent with the finding of Dawite and Ahmed [7] who reported $0.56 \%$.

The higher prevalence rate of reproductive problems in crossbred animals $38.7 \%(\mathrm{n}=151)$ than local breed $4.4 \%$ $(n=17)$ may be due to the fact that European breeds are less adapted to tropical conditions of high temperature and humidity, disease and low feed quality than zebu cattle [23] making them more susceptible than indigenous zebu. Another reason may also be due to the fact that, cross breeds require more elaborated management, feeding and better health care than the indigenous zebu to get better reproductive performance and productivity in the tropics [33].

The significantly higher occurrence of reproductive health problems observed in pluriparus cows (70.97\%) in this work is similar to the previous findings [20,19] which is possibly due to the repeated exposure of the genital tract of pluriparus cows to environmental risk factors that can impart uterine infection. Moreover, in this study, the prevalence of reproductive problems had significant relationship $(\mathrm{P}<0.05)$ with the body condition of the animals. The higher prevalence of reproductive problems found in animals of poor body condition may be attributed to the fact that such animals do have weak expulsive force to drop their after birth or to give birth without assistance 
which is followed by secondary complication. However, animals in good body condition have been reported to have better ability to meet the energy requirement of parturition, lactation and involution of uterus than a cow in poor body condition and hence, are better resistant to the possible infections that may be the result than a cow in poor body condition [12].

The higher percentage of anoestrus (48.48\%) and repeat breeder $(42.4 \%)$ in heifer was reported, this might be due to poor nutrition and management system such as poor body condition, inaccurate record keeping, failure to detect estrus, improper semen handling, and improper time of insemination.

The current finding of higher prevalence rate of reproductive problems obtained in animals under semiintensive $(46.7 \%)$ than those under intensive $(41.4 \%)$ and extensive $(45.9 \%)$ management practice is in agreement with previous studies $[33,16]$. This might be related to poor sanitation of the barn, resulting in contamination during calving, improper feeding and trauma.

The finding of higher prevalence of reproductive health problems in cattle with relatively poor body condition (body condition score 1 and 2) compared to those with good body condition ( $\mathrm{BCS}=3$ and 4 ) agree with previous explanations that indicated cows in poor condition are the most susceptible to reproductive health problems due to the weak expulsive force to expel out the fetal membranes leading to secondary complications [28] and the poor body defense mechanism that increases the rate of infection [15].

\section{Conclusion}

This study revealed that reproductive health problems particularly of repeat breeder, anestrous, RFM, and dystocia were the major causes of low reproductive performance of dairy farms in urban and per urban areas of Hosanna. The Possible risk factors responsible for the occurrence of reproductive health problems identified include body condition and parity. Therefore, an improvement in management system and proper selection of bulls for breeding is essential.

\section{References}

[1] Amene, F. (2006). "Studies on reproductive performance and major reproductive health problems of HF cows at Alage dairy farm. MSc Thesis, Addis Ababa University, Faculty of Veterinary Medicine. DebreZeit, Ethiopia,"unpublished.

[2] Arthur, G.H., Noakes, D.E. and Pearson, H. (1989). Veterinary Reproduction and Obstetrics. Theriogenology $6^{\text {th }}$ ed. Baillier Tindall UK, Pp. 83-85.

[3] Arthur, G.H., Noakes, D.E., Pearson, H. and Perkinson, T.J. (1996). Veterinary Reproduction and Obstetrics.Theriogenology, $4^{\text {th }}$ ed. Bailliere. Tindal. Great Britain. Pp. 291-301.
[4] Befekadu, U. (2007). "A field investigation of delayed resumption of postpartum ovarian activity and prolonged postpartum anestrus in cross bred dairy cows in DebreZeitdairy herds. MSc Thesis, Addis Ababa University, Faculty of Veterinary Medicine, DebreZeit, Ethiopia," unpublished.

[5] Bekena, M., Ekman, T. and Kindhal, H. (2011). The major reproductive health problems in small holder dairy production in and around Nazareth town, central Ethiopia. $J$. Dairy Sci, 71:2572-2583.

[6] DACA, (2006). Standard veterinary treatment guide lines for vet.practice $1^{\text {st }}$ ed. Pp3-13.

[7] Dawite,T.,and Ahmed,S. (2013). Reproductive health problems of cows under different management systems in kombolcha, North east Ethiopia, Hawassa University, School of Veterinary Medicine, Hawassa, Ethiopia. Adva in Biological Res, 7(3):104-108.

[8] Erb, H, W. and Martin, S.W. (1980). Inter-relationship between production and reproductive disease in Holstein cows. J. Diary. Sci, 63: 1911-1917.

[9] Gashaw, A., Worku, F and Mulugeta, S. (2011). Assessment of small holder dairy production system and their reproductive health problems in Jimma town South Weast Ethiopia, Jimma University College of Agriculture and veterinary medicine,Jimma, Ethiopia. Intern. J. of Appl Rese, 9(1): 80-86.

[10] Gebremariam, T. (1996). "Survey on major prepartum and postpartum reproductive problems of dairy cattle in Mekele and its environments. DVM Thesis. Faculty of Veterinary Medicine, Addis Ababa University, DebreZeit, Ethiopia," unpublished.

[11] Hadush,A., Abdella,A., and Regassa, F. (2013). The Major prepartum and postpartum reproductive problems of dairy cattle in Central Ethiopia. J of Vet. Med and Anim Health. 5(4):118-123.

[12] Hafez, E.S.E, (1993). Reproduction in farm animals. $4^{\text {th ed }}$. Lea and Febiger, Philadelphia, Pp. 13-25.

[13] Hoojjer.G.A., Frankena, K.,Varks, M.M.H., and Shuving, M (1999). Treatment of cystic ovarian disease in dairy cows with gonadothrophin releasing hormone. Vet Quarterly, 22:33-37.

[14] Hunduma, D. (2013). The major reproductive disorders of dairy cows in and around Asella town, Central Ethiopia. $J$. of Vet. Med. and Animal Health, 5(4):113-117.

[15] Isahk, M.A., Larson, L.L., Owen, F.G., Lowry, S.R. and Erickson, E.D. (1983). Effect of selenium, vitamin and ration fiber on placental retention and performance of dairy cattle. J. Dairy Sci, 66: 99-106.

[16] Kassahun, M. (2003). "Major clinical reproductive problems of smallholder dairy cows in and around Awassa. DVM thesis, Faculty of Veterinary Medicine, Addis Ababa University, DebreZeit, Ethiopia," unpublished.

[17] Kidusan, K. (2009). "Study on major reproductive disorders of dairy cattle in and around Wukro, DVM Thesis, College of Veterinary Medicine, Mekelle University,Tigray, Northern Ethiopia," unpublished. 
[18] Lobago, F., Bekana, M., Gustafsson, H. and Kindahl, H. (2006). Reproductive performances of dairy cows in smallholder production system in Selalle, Central Ethiopia. Trop. Anim.Health Prod, 38:333-342.

[19] Mamo, T. (2004). "Study on major postpartum reproductive problems of smallholder dairy cows in and around DebreZeit. DVM Thesis, Faculty of Veterinary Medicine, Addis Ababa University, DebreZeit, Ethiopia," unpublished.

[20] Micheal, K. (2003). "Major clinical reproductive problem of small holder dairy cows in and around Hawassa. DVM Thesis, Addis Ababa University, Faculty of Veterinary Medicine, DebreZeit, Ethiopia," unpublished.

[21] Molalegne, B. and Shiv, P. (2011). Study on Major Reproductive Health Problems in Indigenous and Cross Breed Cows in and Around Bedelle, South West Ethiopia. J. Anim. Vet. Adv, 10(6):723-727.

[22] Msangi, B.S., Bryant, M.J. and Thorne, P.J. (2005). Some factors affecting variation in milk yield in crossbred dairy cows on smallholder farms in North-East Tanzania. Trop. Anim.Health Prod, 6: 403-412.

[23] Mukasa-Mugerwa, E. (1989). A review of reproductive performance of female Bos indicus (Zebu) cattle. ILCA monograph No. 6. ILCA, Addis Ababa.

[24] Noakes, D.E. (1986). Fertility and Obstetrics in cattle. Oxford (UK) Black well Sci. Pub. Pp28-30.

[25] Radostits, O.M., Leslie, K.E. and Fetrow, J. (1994). Herd health; Food Animal Production medicine. $2^{\text {nd }} e d, W . B$ Saunders company.

[26] Radostits, O. M. (2001). Herd health; Food Animal Production medicine. $2^{\text {nd }}$ ed, W.B. Saunders Company.

[27] Richard, W. (1993). Dairying. Tropical Agriculturalist, $1^{\text {st }}$ Ed. Macmillan Press London. Pp.43-48.
[28] Robert, S.J. (1986). Veterinary Obstetrics and genital diseases.Theriogenology 3rd ed. Edwards' Brothers, Inc., Michigan, Pp. 48-104.

[29] Shiferaw, Y., Tenhagen,B.A., Bekana,M. and Kassa,T. (2005). Reproductive disorders of crossbred dairy cows in the central highlands of Ethiopia and their effect on reproductive performance. Trop. Anim. Health Prod., 37: 427-441.

[30] Simret, H. (2010). "Major reproductive disorders of dairy cows in and around mekelle. DVM thesis,college of Veterinary Medicine, Mekelle University, Mekelle, Ethiopia," unpublished.

[31] SPSS, (2010). Statistical Package for Social Sciences Inc. version 16.

[32] Stevenson, J.S. and Call, E.P. (1988). Reproductive disorders in the peri parturient dairy cows. J. Dairy Sci.7(1):2572-2583.

[33] Tekelye, B., Kasali,O.B. and Tsion, A. (1991). Reproductive problems in cross breed cattle in central Ethiopia. Animal Reproduction Science, 26: 41-49.

[34] The Economist Intelligence Unit, (2007). Country Report for Ethiopia, January, 2007. The Economist Intelligence Unit, 26 Red Lion Square, London.WCIR4HQ, UK.

[35] Zegeye, Y. (2003). Imperative and challenges of dairy production, processing and marketing in Ethiopia. In: Jobre, Y. and Gebru, G. challenges and opportunities of livestock marketing in Ethiopia proceeding of the $10^{\text {th }}$ annual conference of the Ethiopia society, Theriognology, 43: 9891000. Animal production (ESAP) Held in Addis Ababa, Ethiopia, 22-24 August 2002. ESAP, Addis Ababa Ethiopia, Pp: 61-67. 